\title{
High-efficiency extraction and modification on coal liquefaction residue using supercritical fluid with different types of solvents
}

Xiongchao Lin ${ }^{\mathrm{a}^{*}}$, Shouyi $\mathrm{Li}^{\mathrm{a}}$, Fenghua Guo ${ }^{\mathrm{a}}$, Guangce Jiang ${ }^{\mathrm{a}}$, Xujun Chen ${ }^{\mathrm{b}}$, Yonggang Wang ${ }^{\mathrm{a}}$

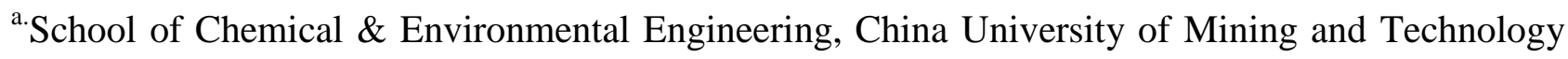
(Beijing), D11 Xueyuan Road, Haidian District, Beijing 100083, People's Republic of China.

${ }^{\mathrm{b}}$ Department of Chemical Engineering, Curtin University of Technology, GPO Box U1987, Perth Western Australia 6845, Australia

* Correspondence author: X.C.Lin, D11 Xueyuan Road, Haidian District, Beijing 100083, P.R. China. Tel: +86-10-6233-1048; E-mail address: linxiongchao@163.com 


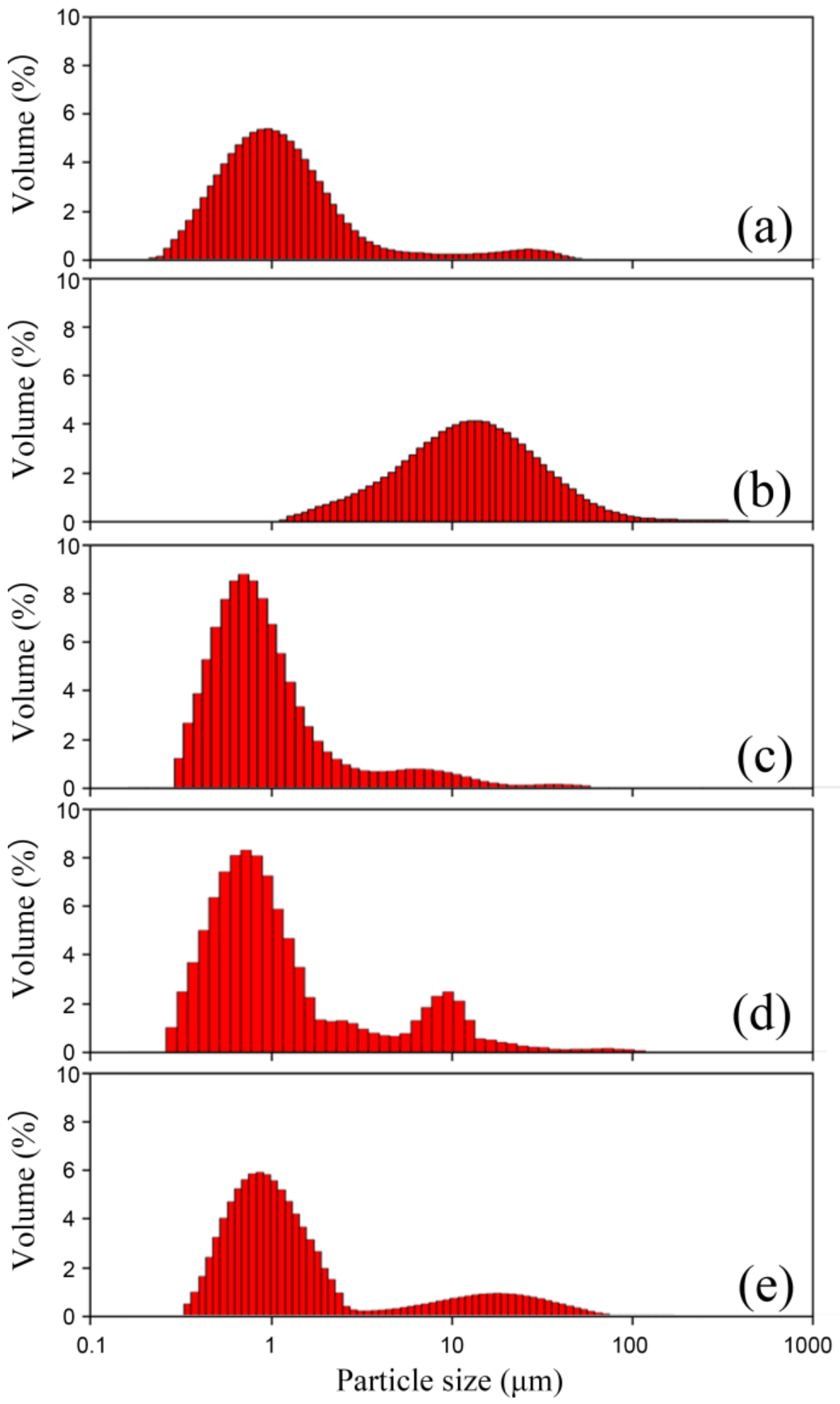

Figure S1 The particle size distribution of a) coal tar-QI; b) raw CLR-QI; c) SFE-A QI; d) SFE-P QI; and e) SFE-B QI. 


\section{Montage Photograph}
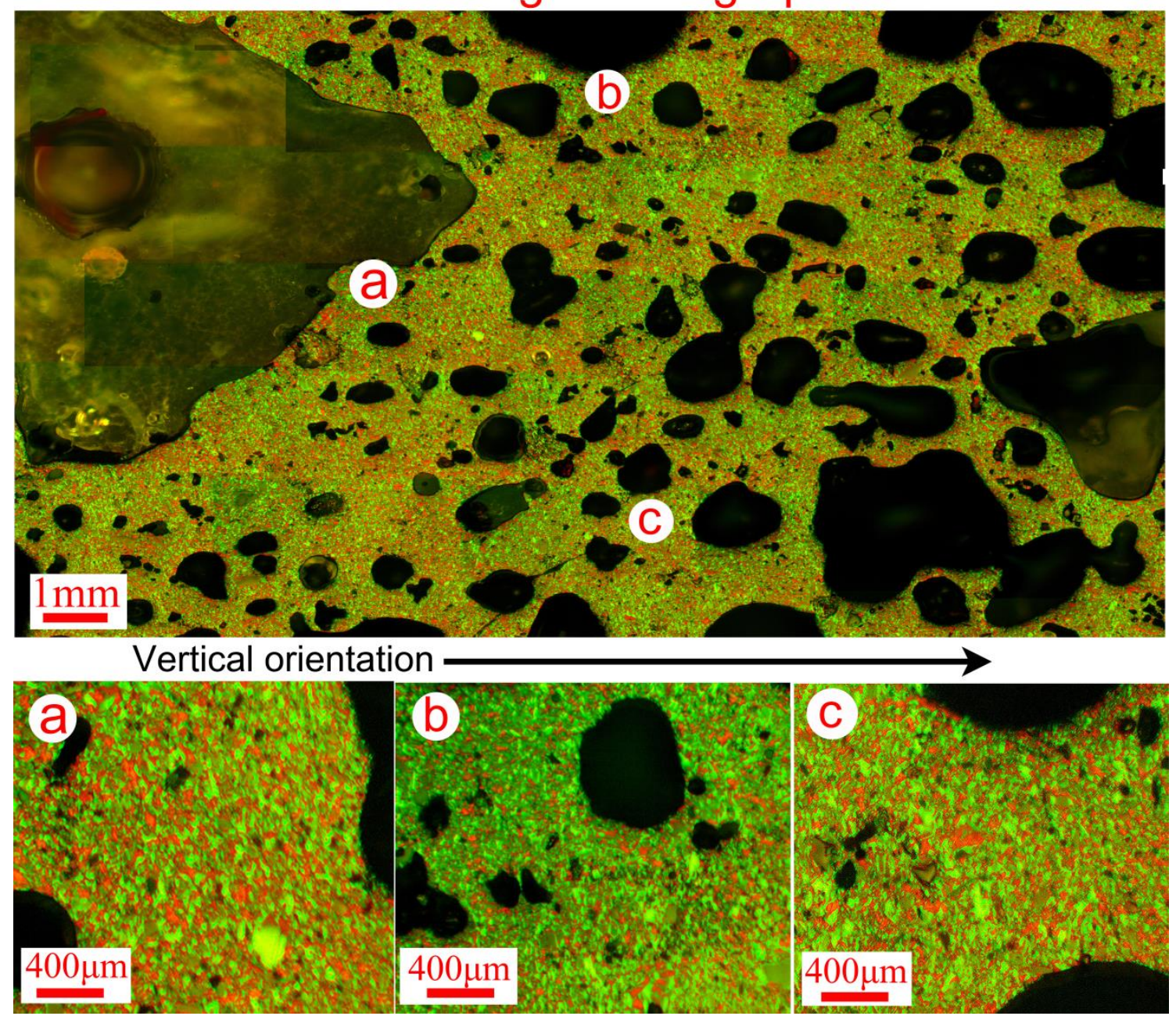

Figure S2 Montage photographs and enlarged photomicrographs of the coke lump produced at 463

${ }^{\circ} \mathrm{C}$ under 1 bar from the raw CLR. 
Montage Photograph
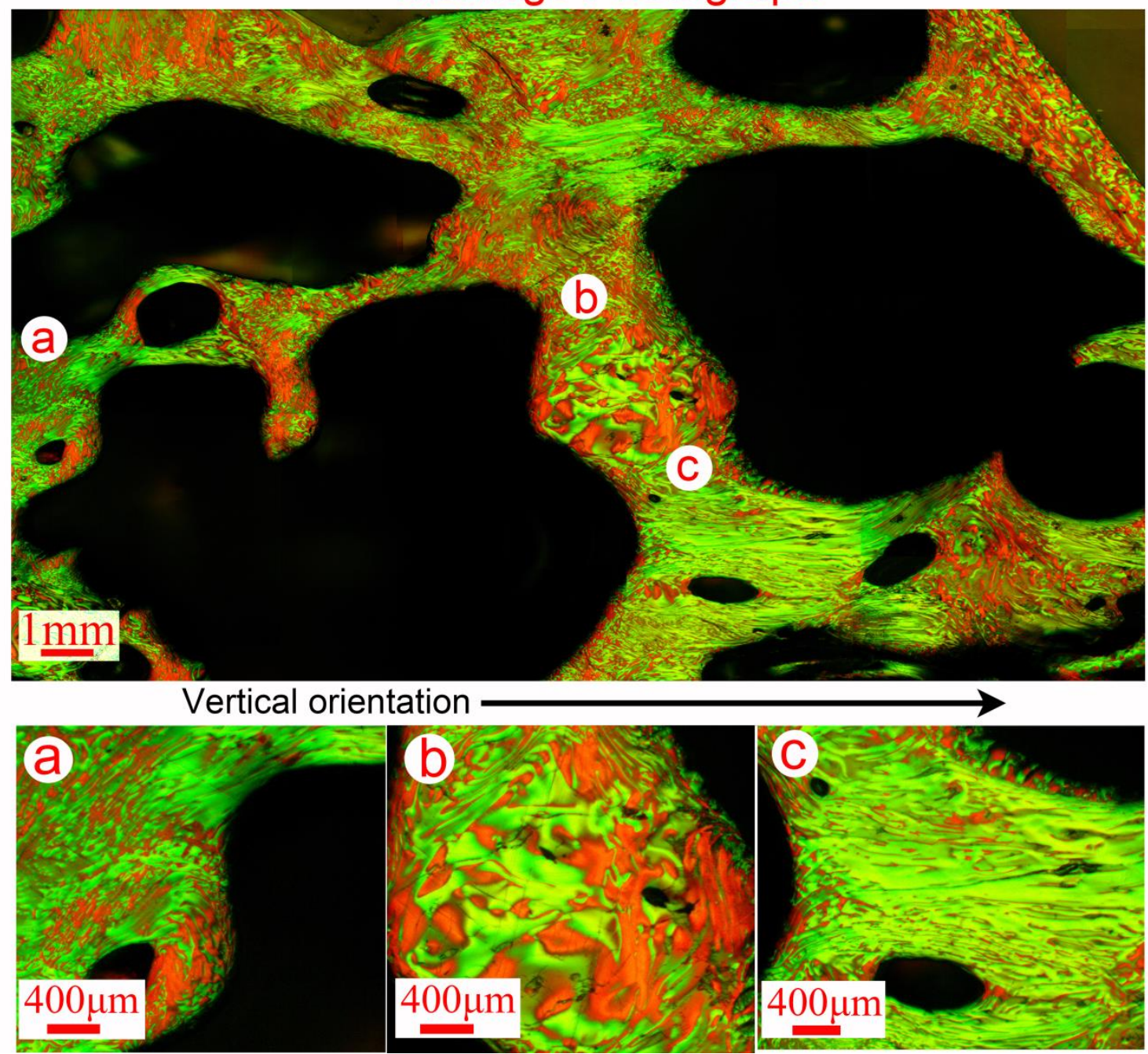

Figure S3 Montage photographs and enlarged photomicrographs of the coke lump produced at 463

${ }^{\circ} \mathrm{C}$ under 1 bar from the SFE-A extract. 

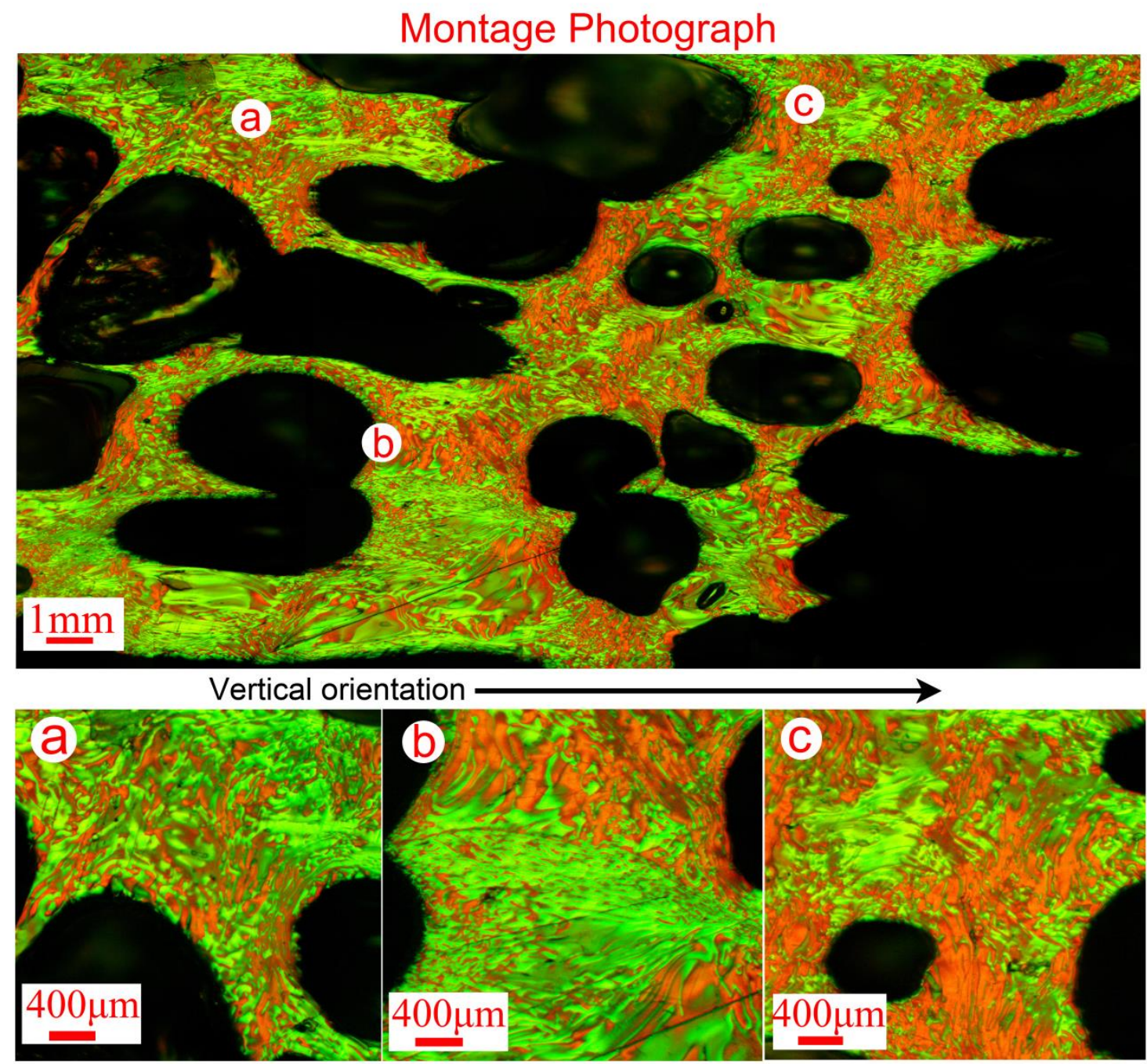

Figure S4 Montage photographs and enlarged photomicrographs of the coke lump produced at 463

${ }^{\circ} \mathrm{C}$ under 1 bar from the SFE-P extract. 


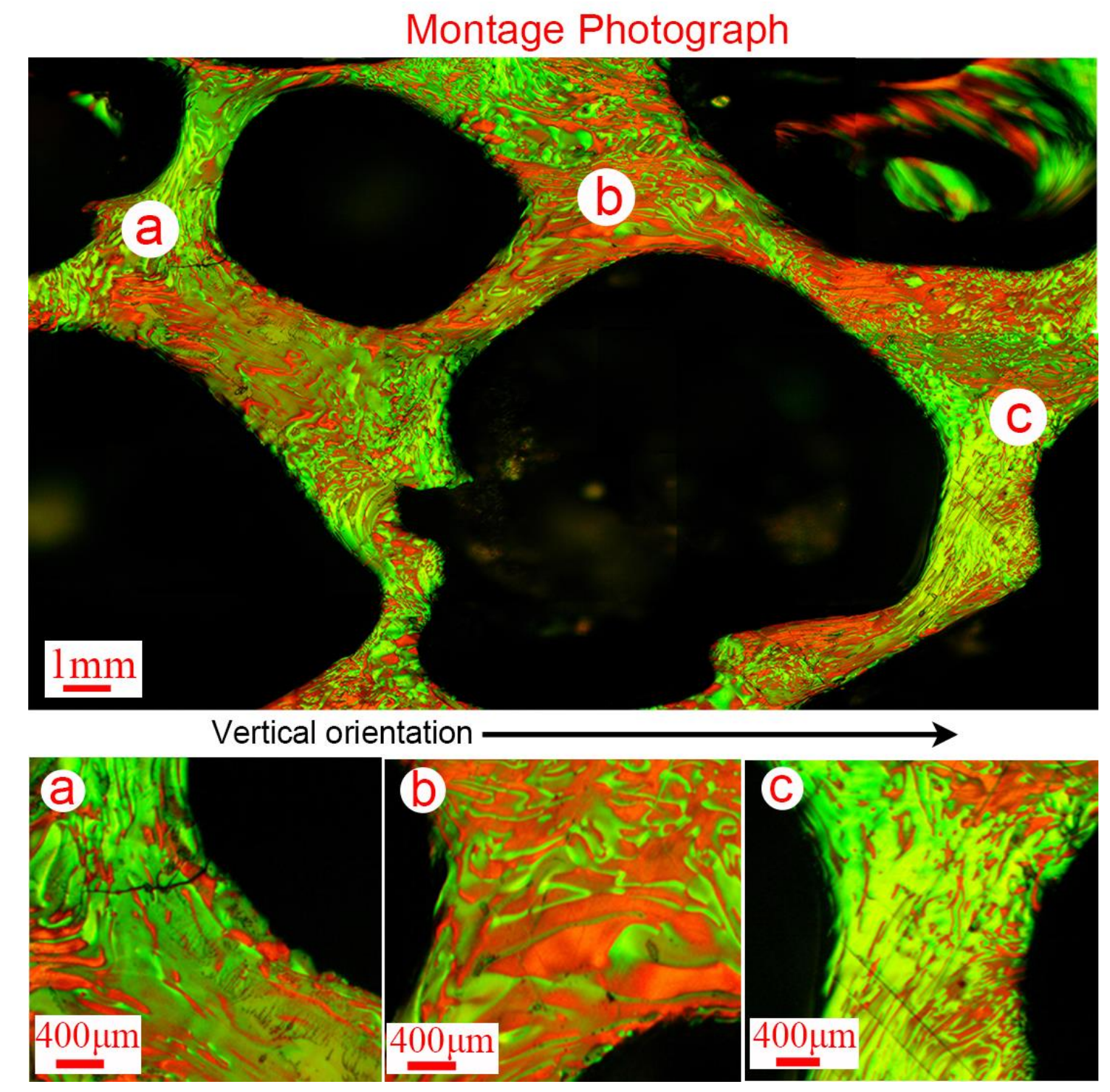

Figure S5 Montage photographs and enlarged photomicrographs of the coke lump produced at 463 ${ }^{\circ} \mathrm{C}$ under 1 bar from the SFE-B extract. 